\title{
Thermoregulation During Extended Exercise in the Heat: Comparisons of Fluid Volume and Temperature
}

\author{
Walter S. Hailes, MS; John S. Cuddy, MS; Kyle Cochrane, MS; Brent C. Ruby, PhD \\ From the University of Montana, Montana Center for Work Physiology and Exercise Metabolism, Missoula, MT.
}

\begin{abstract}
Objective.-This study aimed to determine the physiological and thermoregulatory responses of individuals exercising in the heat (US military red flag conditions, wet-bulb globe temperature $31.5-32.2^{\circ} \mathrm{C}$ ) while consuming varied volumes of ambient temperature water and ice slurry.

Methods.-Participants $(\mathrm{N}=12)$ walked on a treadmill for 3 hours at approximately $40 \%$ peak aerobic capacity in a hot environment while consuming ambient temperature $\left(35.5^{\circ} \mathrm{C}\right)$ water $(\mathrm{W})$, ice slurry $\left(0^{\circ} \mathrm{C}\right.$, two-thirds shaved ice and one-third water) at a ratio of $2 \mathrm{~g} \cdot \mathrm{kg}^{-1}$ body mass every 10 minutes (FS), and reduced volume ice slurry as described at a rate of $1 \mathrm{~g} \cdot \mathrm{kg}^{-1}$ body mass every 10 minutes (HS). Trials were completed at least 14 days apart, in a randomized, repeated measures design.

Results.-Percent body weight loss was higher during the HS trial $(1.8 \pm 0.01 \%)$ compared with FS $(0.5 \pm 0.01 \% ; P<.001)$ and $\mathrm{W}(0.6 \pm 0.01 \% ; P<.001)$. Mean rectal temperature at 3 hours was lower during FS $\left(37.8 \pm 0.7^{\circ} \mathrm{C}\right)$ compared with $\mathrm{HS}\left(38.1 \pm 0.8^{\circ} \mathrm{C}\right)$ and $\mathrm{W}\left(38.2 \pm 0.8^{\circ} \mathrm{C}\right)(P=.04 \mathrm{vs}$ HS, and $P=.005$ vs W, main effect for trial). No differences were found in rectal temperature between HS and W. Heart rate was lower at the end of the third hour during FS (141 \pm 10 beats/min) compared with HS $(157 \pm 19$ beats $/ \mathrm{min})$ and $\mathrm{W}(154 \pm 18$ beats $/ \mathrm{min})(P=.001$ and $P=.007$, respectively, time $\times$ trial interaction). There were no differences in heart rate between HS and W.

Conclusions. - The temperature of consumed fluids may be as important as the volume for the management of thermoregulation and other physiological responses for extended work in hot environments.
\end{abstract}

Key words: hydration, hyperthermia, heat stress, rectal temperature

\section{Introduction}

Vocations such as military training, wildland fire suppression, and varied athletic/recreational pursuits require humans to work or exercise in hot environments for extended periods of time. These activities also mandate the self-transport or frequent resupply of fluid to sustain performance for the duration of the work shift or event. ${ }^{1}$ For these individuals the weight of fluid that must be carried increases the metabolic demand and subsequent heat production, posing hindrances to completing the job or event. ${ }^{2}$ These individuals must determine and selfmanage the necessary fluid requirements to stay safe

Corresponding author: Brent C. Ruby, PhD, Department of Health and Human Performance, University of Montana, McGill Hall - HHP, Missoula, MT 59812-1825 (e-mail: brent.ruby@mso.umt.edu).

Submitted for publication January 2016.

Accepted for publication June 2016. without carrying excess weight that will reduce work output or exercise performance.

Fluid consumption is vital during exercise in hot environments because it allows the body to preserve plasma volume and sweat rate. Preserving plasma volume allows individuals to maintain cardiac output and physical performance. In humans, it has been established that rectal temperature is disproportionately increased during exercise in hot environments when inadequate fluid intake results in hypohydration compared with euhydration. ${ }^{3-6}$ The compilation of these studies has been translated into a standardized approach to fluid intake to prevent excessive dehydration (greater than $2 \%$ body mass loss) that can degrade performance and increase the risk of heat injury during extended work in all environments. ${ }^{7,8}$ However, the present drinking guidelines provide little information about the appropriate temperature of ingested fluids. ${ }^{7,8}$ 
Numerous studies have demonstrated that ingesting cold fluids improves performance and/or lowers physiological stress metrics to varied types of exercise in warm to hot environments. ${ }^{9-14}$ Mündel et $\mathrm{al}^{15}$ found that participants who drank ad libitum consumed more cold fluid and gained a subsequent performance advantage (increased time to exhaustion on a cycle ergometer) than when they were provided ambient temperature fluid ad libitum. Several studies have also found lower whole body sweat production as a result of cold water ingestion..$^{10,11,16-18}$ Based on these previous data, it seems possible to reduce fluid volume while maintaining healthy hydration and thermoregulatory status by consuming cold fluids. If ingestion of cold fluids can reduce fluid needs, individuals with access to cold fluids and/or ice who are required to carry their own water supply, like military personnel, wildland firefighters, and endurance athletes, will be able to lighten their fluid load without compromising thermoregulatory safety.

The purpose of this study was to determine the physiological and thermoregulatory responses of individuals exercising in the heat (military red flag conditions, wet-bulb globe temperature $31.5-32.2^{\circ} \mathrm{C}$ ) while consuming varied volumes of ambient temperature water and ice slurry. We hypothesized that 1 ) ice slurry would reduce physiological and thermoregulatory strain compared with the same volume of water, and 2) consuming one half the volume of ice slurry (equal to one half the recommended volume for these environmental conditions) compared with ambient temperature water (recommended volume for these environmental conditions) would result in no difference in physiological and thermoregulatory strain. ${ }^{19}$

\section{Methods}

\section{PARTICIPANTS}

Recreationally active men $(\mathrm{N}=12,24 \pm 4$ years $)$ were recruited from the university and local community to take part in the study. Participants passed a prescreening Physical Activity Readiness-Questionnaire and read and signed an informed consent form that was approved by the university Institutional Review Board before participating in the study. Twelve participants were recruited, all of whom completed the entire data collection process.

\section{PRELIMINARY TESTING}

\section{Hydrodensitometry}

Body composition was assessed via an underwater weighing tank (Exertech, Dresbach, MN) utilizing estimated residual volume based on height and weight. Participants were required to fast for $\geq 3$ hours prior to testing. Dry weight was determined using a digital scale (Befour Inc, Cedarburg, WI), and height was measured.
Participants were weighed while completely submerged. Body density and percent body fat were estimated using the Siri equation. ${ }^{20}$

\section{Peak aerobic capacity}

Participants fasted for $\geq 3$ hours prior to arrival for $\mathrm{VO}_{2}$ peak testing. A running graded exercise test to volitional exhaustion, using the Bruce protocol, was performed on a treadmill ergometer (TMX225C, Fullvision Inc, Newton, KS). ${ }^{21}$ Participants' expired gas was analyzed every 15 seconds by a metabolic cart (Parvomedics Inc, Sandy, UT) for the duration of the treadmill test. Heart rate was monitored and recorded using a heart rate watch and chest strap (Polar Electro, Kempele, FL).

\section{EXPERIMENTAL TRIALS}

\section{Exercise protocol}

The experimental trials consisted of 3 visits to the laboratory, with each visit separated by approximately 14 days to minimize carryover acclimation between trials. Participants arrived at the laboratory after completing an 8-hour fast. Participants maintained a 24-hour dietary $\log$ before their first trial and replicated this for the subsequent trials. Additionally, participants maintained a physical activity log for 48 hours before their first trial and replicated this for the additional trials. Participants were instructed to refrain from exercise for 24 hours before each trial, except for activities of daily college life (ie, walking or bike riding for transportation).

Upon arrival at the laboratory, participants consumed $200 \mathrm{~mL}$ of cool water, provided a urine sample, and had nude body weight measured (CW-11, Ohaus, Pine Brook, NJ). Urine specific gravity (USG) was measured before and after each trial (PAL-10S, Atago, Cohasset, MA). A $5 \mathrm{~mL}$ blood sample was collected using a venipuncture technique before and immediately after exercise. These samples were collected to evaluate changes in plasma electrolytes, hemoglobin, and hematocrit using the iSTAT CHEM8+ (Abbott Point of Care Inc, Princeton, NJ). Participants were then outfitted with 2 skin temperature sensors (T200, PhysiTemp, Clifton, $\mathrm{NJ})$ to monitor changes in skin temperature $\left(\mathrm{T}_{\mathrm{s}}\right)$. Sensors were placed on the chest approximately $5 \mathrm{~cm}$ above the left nipple on the pectoralis muscle and on the back (subscapular region) at a similar level. Skin temperature collection sites (chest and back) were combined into a single mean value for analysis. Rectal temperature $\left(T_{r}\right)$ was continuously monitored (Mon-a-therm GP, Mallinckrodt Medical Inc, St. Louis, MO) throughout the duration of the trial. $T_{\mathrm{r}}$ and $\mathrm{T}_{\mathrm{s}}$ were collected using DASYLab v12.0 Software (Measurement Computing 
Co, Norton, MA). Heart rate was monitored with a heart rate watch and chest strap (Polar Electro, Kempele, FL).

Participants walked on a motorized treadmill (TMX225C, Fullvision Inc, Newton, KS) for a total of 3 hours, using a work-to-rest ratio of 25 minutes of walking and 5 minutes of standing rest in a temperature and humidity controlled room (Tescor Inc, Warminster, PA) $\left(35.5^{\circ} \mathrm{C}, 50 \%\right.$ relative humidity, wet-bulb globe temperature approximately $31^{\circ} \mathrm{C}$ ) at a workload that approximated $40 \%$ of each participant's $\mathrm{VO}_{2}$ peak. Walking speed and grade were reduced if the participant was having a difficult time maintaining pace. Alterations in work rates were repeated for each subsequent trial.

During each 3-hour trial, participants received 1 of 3 fluid treatments in a randomized order: (W) water $\left(35.5^{\circ} \mathrm{C}\right.$, equivalent to temperature of exercise environment) at a ratio of $2 \mathrm{~g} \cdot \mathrm{kg}^{-1}$ body mass every 10 minutes, (FS) ice slurry $\left(0^{\circ} \mathrm{C}\right.$, composed of two-thirds shaved ice and one-third water by unit mass) at a ratio of $2 \mathrm{~g} \cdot \mathrm{kg}^{-1}$ body mass every 10 minutes, and (HS) ice slurry $\left(0^{\circ} \mathrm{C}\right.$, composed of two-thirds shaved ice and one-third water by unit mass) at a rate of $1 \mathrm{~g} \cdot \mathrm{kg}^{-1}$ body mass every 10 minutes. Fluid intake rate $\left(2 \mathrm{~g} \cdot \mathrm{kg}^{-1}\right.$ body mass every 10 minutes) was chosen, based on previous research in our laboratory, in an attempt to maintain euhydration and allow the ice/water mixture to be consumed while minimizing the discomfort associated with quick consumption of slurry (ie, brain or chest freeze). At the halfway point of the trial (ie, 90 minutes), participants consumed a snack (Snickers or chocolate chip Clif bar). The same snack item was used for each participant's 3 trials. Upon completion of each trial, participants provided a nude weight, urine sample, and $5 \mathrm{~mL}$ of blood.

\section{Physiological strain index}

Physiological strain index (PSI) was calculated using the equations developed by Moran and associates. ${ }^{22}$

\section{Sweat loss}

Using the equation below, sweat loss was calculated by using changes in pre- and post-trial nude body mass, urine output, fluid intake, and estimated respiratory water loss.

$$
\begin{aligned}
\text { SweatLoss }(L) & =\left(B W_{\text {pre }}[k g]+\text { Liquid Ingested }[k g]\right) \\
& -\left(\begin{array}{c}
B W_{\text {post }}[k g]+\text { UrineWeight }[\mathrm{kg}] \\
+ \text { RespiratoryWaterLoss }[\mathrm{kg}]
\end{array}\right)
\end{aligned}
$$

Using the equation developed by Mitchell et al, ${ }^{23}$ and using the American College of Sports Medicine prediction equation $^{24}$ for oxygen consumption while walking, respiratory water loss was calculated.

$M_{e}=0.019 \cdot \mathrm{VO}_{2}(L / \mathrm{min}) \cdot\left(44-P_{a}\right)$

$\mathrm{M}_{\mathrm{e}}=$ rate of evaporative water loss $(\mathrm{g} / \mathrm{min})$

$\mathrm{P}_{\mathrm{a}}=$ water vapor pressure $(\mathrm{mm} \mathrm{Hg})$

Water vapor pressure was determined as per Fox et $\mathrm{al}^{25}$ :

$$
\begin{aligned}
& \mathrm{P}_{a}=13.955-.6584 T+0.0419 T^{2} \\
& \mathrm{~T}=\text { temperature }\left({ }^{\circ} \mathrm{C}\right)
\end{aligned}
$$

\section{STATISTICAL ANALYSIS}

Analysis of rectal temperature, skin temperature, heart rate, and rating of perceived exertion (RPE) were analyzed using $3 \times 4$ repeated measures analysis of variance (ANOVA). PSI was analyzed using $3 \times 3$ repeated measures ANOVA. Blood electrolytes (sodium, chloride, and potassium) and USG were analyzed using $3 \times 2$ repeated measures ANOVA. One-way repeated measures ANOVA was used to analyze sweat rate and plasma volume shift. All pairwise post hoc tests were adjusted using the Bonferroni method. Statistical analyses were done using SPSS 22.0 (IBM, Chicago, IL). Statistical significance was evaluated at the $P<.05$ level. Data are reported as mean $\pm \mathrm{SD}$, unless otherwise noted.

\section{Results}

Twelve participants (height $176.2 \pm 6.5 \mathrm{~cm}$, weight 73.9 $\pm 9.5 \mathrm{~kg}, 9.7 \pm 5.1 \%$ body fat, $\mathrm{VO}_{2}$ peak $61.5 \pm 7.9$ $\mathrm{mL} \cdot \mathrm{kg}^{-1} \cdot \mathrm{min}^{-1}$ ) completed all trials. Data for 1 participant were removed from the rectal temperature data set due to several malfunctions of the rectal temperature probe. Data for 2 participants were removed from the skin temperature data due to incomplete data collection. All other reported data include all 12 participants.

\section{FLUID INTAKE}

Total fluid intake was significantly higher during the FS and $\mathrm{W}$ compared with the HS $(P<.001)$. Mean fluid consumption was $797 \pm 90 \mathrm{~mL} \cdot \mathrm{h}^{-1}$ during FS and W trials and $421 \pm 62 \mathrm{~mL} \cdot \mathrm{h}^{-1}$ during the HS trial. The range of fluid consumption was $697-968 \mathrm{~mL} \cdot \mathrm{h}^{-1}$ for FS and $\mathrm{W}$ and $330-492 \mathrm{~mL} \cdot \mathrm{h}^{-1}$ during the $\mathrm{HS}$ trial.

\section{RECTAL TEMPERATURE}

The main effect of trial was significant $(P<.05)$ for the measure of rectal temperature $(n=11)$. Overall, rectal temperature was lower during FS $\left(37.8 \pm 0.7^{\circ} \mathrm{C}\right)$ compared with HS $\left(38.1 \pm 0.8^{\circ} \mathrm{C}\right)(P=.04)$. Similarly, 


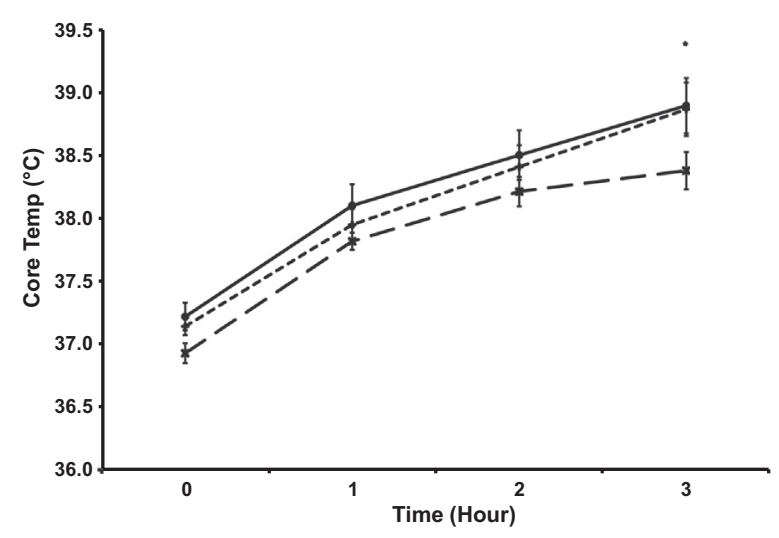

Figure 1. Rectal temperature $\left({ }^{\circ} \mathrm{C}\right)$ response during the 3-hour heat stress trials $(\mathrm{n}=11)$. Values are mean \pm SEM. ${ }^{*} P<.05$ vs FS, main effect. $-x$ - Full Slurry -+- Half Slurry - $\bullet$ - Water

FS was significantly lower than $\mathrm{W}\left(38.2 \pm 0.8^{\circ} \mathrm{C}\right)(P=$ .005). However, there were no differences in the rectal temperature response between HS and W (Figure 1).

\section{SKIN TEMPERATURE}

The trial $\times$ time interaction was significant for the measure of skin temperature $(\mathrm{n}=10)(P<.05)$ (Figure 2). Skin temperature was lower during FS (34.5 $\left.\pm 0.8^{\circ} \mathrm{C}\right)$ at hour 3 compared with $\mathrm{HS}\left(36.8 \pm 0.7^{\circ} \mathrm{C}\right.$; $P=.037)$ and $\mathrm{W}\left(36.9 \pm 0.7^{\circ} \mathrm{C} ; P=.019\right)$. However, there was no difference in skin temperature between HS and W.

\section{HEART RATE}

The trial $\times$ time interaction was significant for the measure of heart rate $(\mathrm{n}=12)(P<.05)$ (Figure 3). Heart rate was lower during FS $(141 \pm 10)$ at hour 3 compared with HS $(157 \pm 19 ; P=.001)$ and $\mathrm{W}(154 \pm$

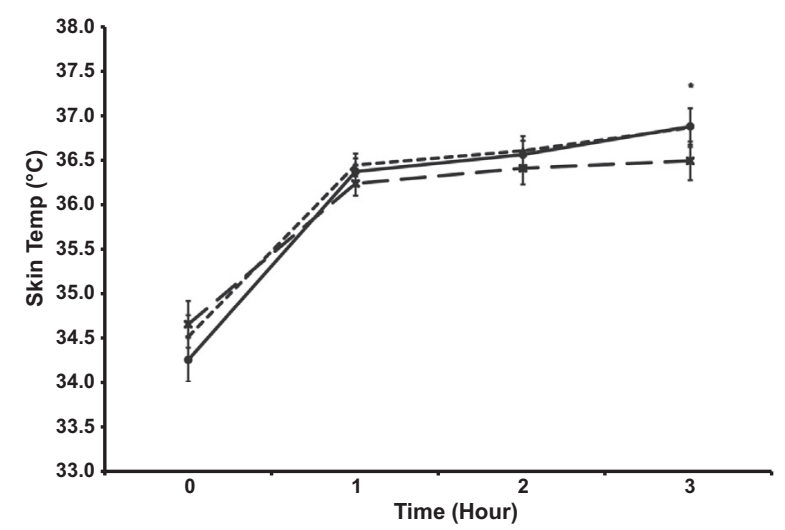

Figure 2. Skin temperature $\left({ }^{\circ} \mathrm{C}\right)$ response during the 3-hour heat stress trials $(\mathrm{n}=10)$. Values are mean \pm SEM. ${ }^{*} P<.05$ vs FS, trial $x$ time interaction. $-x-$ Full Slurry -+- Half Slurry -•- Water

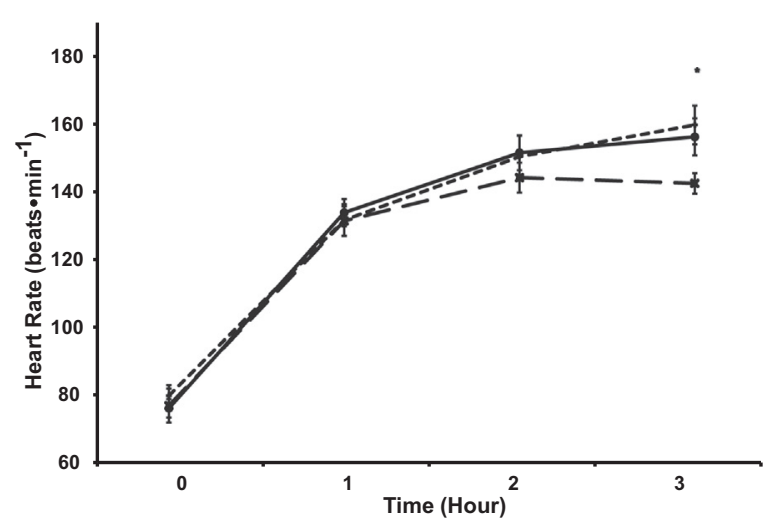

Figure 3. Heart rate (beats $\cdot \mathrm{min}^{-1}$ ) response during the 3-hour heat stress trials $(\mathrm{n}=12)$. Values are mean \pm SEM. ${ }^{*} P<.05$ vs FS, trial $x$ time interaction.- $\times$ - Full Slurry -+- Half Slurry - $\bullet$ - Water

$18 ; P=.007)$. However, there was no difference in heart rate between HS and W.

\section{PHYSIOLOGICAL STRAIN INDEX}

The trial $\times$ time interaction was significant for the measure of PSI $(\mathrm{n}=11)(P<.05)$ (Figure 4). PSI was lower during FS $(5.5 \pm 1.4)$ at hour 2 compared with HS $(6.1 \pm 1.9 ; P=.03)$ and $\mathrm{W}(6.3 \pm 2.01 ; P=$ .04). PSI was lower during FS $(5.8 \pm 1.6)$ at hour 3 compared with HS $(7.6 \pm 2.3 ; P<.001)$ and W $(7.5 \pm$ $2.2 ; P=.001)$. However, there were no differences in PSI between HS and W.

\section{PLASMA ELECTROLYTES}

Plasma sodium concentration ([Na]) decreased during each trial but was significantly higher at the end of HS compared with FS $(P<.001)$ and $\mathrm{W}(P<.001)$. Plasma chloride concentration $([\mathrm{Cl}])$ decreased during the FS trial $(P=.014)$, increased during the HS trial

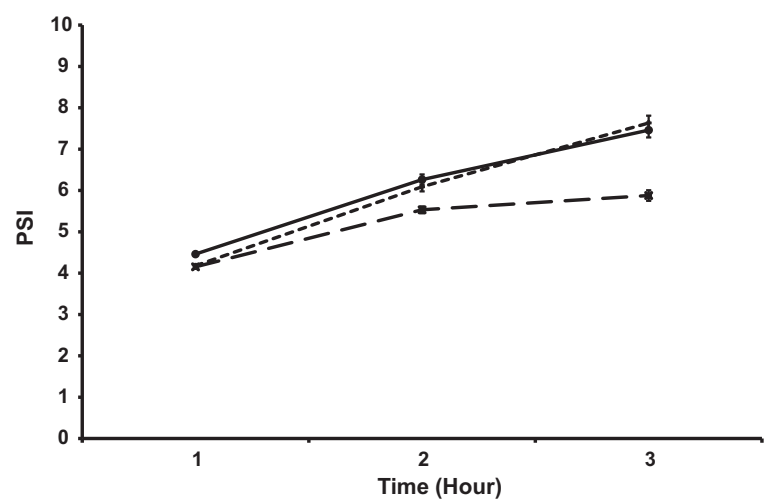

Figure 4. Physiological strain index (PSI) during the 3-hour heat stress trials $(\mathrm{n}=11)$. Values are mean \pm SEM. ${ }^{*} P<.05$ vs FS, time $\times$ trial interaction.- $\times$ - Full Slurry -+- Half Slurry -•- Water 
Table 1. Plasma electrolytes $(\mathrm{n}=12), \mathrm{Na}, \mathrm{Cl}$, and $\mathrm{K}$ concentration before (Pre) and after (Post) the 3-hour heat stress trials

\begin{tabular}{|c|c|c|c|c|c|c|}
\hline \multirow[b]{3}{*}{ Electrolyte } & \multicolumn{6}{|c|}{ Concentration $\left(m m o l \times L^{-1}\right)$} \\
\hline & \multicolumn{2}{|c|}{$F S$} & \multicolumn{2}{|c|}{$H S$} & \multicolumn{2}{|c|}{$W$} \\
\hline & Pre & Post & Pre & Post & Pre & Post \\
\hline$[\mathrm{Na}]$ & $141 \pm 1$ & $138 \pm 1^{*,+}$ & $142 \pm 2$ & $141 \pm 2^{*}$ & $142 \pm 1$ & $138 \pm 2^{*},+$ \\
\hline$[\mathrm{Cl}]$ & $101 \pm 2$ & $99 \pm 1^{*, \dagger}$ & $101 \pm 2$ & $103 \pm 2^{*}$ & $101 \pm 2$ & $100 \pm 1^{\dagger}$ \\
\hline$[\mathrm{K}]$ & $4.1 \pm 0.3$ & $4.3 \pm 0.2^{*}$ & $4.0 \pm 0.3$ & $4.5 \pm 0.3^{*}$ & $4.0 \pm 0.2$ & $4.4 \pm 0.2^{*}$ \\
\hline
\end{tabular}

* $P<.05$ compared with Pre, trial $\times$ time interaction.

${ }^{\dagger} P<.05$ compared with HS, trial $\times$ time interaction.

$(P=.045)$, and did not change during the $\mathrm{W}$ trial $(P=$ .153). Plasma chloride concentration during both FS and W was lower than HS postexercise $(P<.001$ and $P=$ .002 for FS vs HS and W vs HS, respectively). Plasma potassium concentration $([\mathrm{K}])$ increased during each trial pre- to post-trial but was not different between trials (Table 1).

\section{BODY MASS, SWEAT RATE, USG, PLASMA VOLUME, AND RPE}

Participants lost more body mass during the HS trial compared with FS and W, as seen in Table 2. However, there was no difference in body mass loss between FS and $\mathrm{W}$. There was no difference in sweat rate $(\mathrm{n}=12)$ across the 3 trials $(850 \pm 137,839 \pm 156$, and $901 \pm$ $145 \mathrm{~mL} \cdot \mathrm{h}^{-1}$ for FS, HS, and $\mathrm{W}$, respectively). There was no difference in USG $(\mathrm{n}=12)(\mathrm{FS}$ : pre $=1.0135 \pm$ 0.0099 , post $=1.0138 \pm 0.0062 ;$ HS: pre $=1.0140 \pm$ 0.0073, post $=1.0172 \pm 0.0058 ; \mathrm{W}:$ pre $=1.0126 \pm$ 0.0074 , post $=1.0163 \pm 0.0058$ ). There was no difference in plasma volume change from pre to post $(\mathrm{n}=12)$ among the 3 trials $(-4.5 \pm 6.0 \%,-8.4 \pm$ $6.0 \%,-7.4 \pm 6.3 \%$ for FS, HS, and $\mathrm{W}$, respectively). There was no difference in RPE $(\mathrm{n}=12)$ among the 3 trials for FS $(12 \pm 1,13 \pm 1$, and $14 \pm 2$ for hours 1,2 , and 3 , respectively), HS (12 $\pm 1,14 \pm 2$, and $15 \pm 2$ for hours 1,2 , and 3 , respectively), and $\mathrm{W}(12 \pm 1,14 \pm 2$, and $15 \pm 2$ for hours 1,2 , and 3 , respectively).

Table 2. Participants mean body mass (kg) before (Pre) and after (Post) the 3-hours heat stress trials

\begin{tabular}{lccc}
\hline & \multicolumn{3}{c}{ Body mass $(\mathrm{kg})$} \\
\cline { 2 - 4 } Trial & Pre & Post & \% change \\
\hline FS & $73.4 \pm 8.9$ & $73.0 \pm 9.1$ & $-0.5 \pm 0.9^{*}$ \\
HS & $73.2 \pm 8.7$ & $71.9 \pm 8.9$ & $-1.8 \pm 0.8$ \\
W & $73.5 \pm 9.1$ & $73.1 \pm 9.5$ & $-0.6 \pm 0.8^{*}$
\end{tabular}

Percent (\%) body mass changes from pre- to postexercise.

${ }^{*} P<.05$ compared with HS trial.

\section{Discussion}

This study suggests that individuals should consider the effect of both fluid temperature and volume when thermoregulation is important. There were no differences in rectal temperature, heart rate, PSI, skin temperature, sweat loss, or RPE during 3 hours of exercise in the heat when participants were provided half the volume of fluid in the form of $\mathrm{HS}$ in comparison to $\mathrm{W}$. These data indicate that consuming a larger volume of water to closely maintain hydration $(0.6 \pm 0.01 \%$ body mass loss) did not improve physiological or thermoregulatory responses to exercise in the heat compared with consuming ice slurry at a rate that resulted in approximately $2 \%$ body mass loss. These data do not contest previous research, which has demonstrated that consuming fluid in the heat, commensurate with maintaining euhydration ( $<2 \%$ body mass loss), is the best way to mitigate a rise in rectal temperature and heart rate. ${ }^{3-6}$ However, these data do suggest that the consumption of cold fluids at half the total volume provides thermoregulatory outcomes comparable to the ingestion of larger, recommended volumes of ambient temperature fluid.

Rectal temperature, skin temperature, and heart rate were lower after 3 hours of exercise in the heat when participants consumed the same volume of FS compared with W. Physiological strain index was lower during the second and third hours of exercise in the heat when participants consumed the same volume of FS compared with W. These data support previous research that demonstrated improved performance and thermoregulatory responses to exercise when consuming cold fluids. ${ }^{9-14}$

The hypothesis was that participants would be able to exchange the heat sink of the ice slurry and the evaporative cooling of sweat, thereby reducing sweat rate during the FS and HS compared with the W trial. This was not the case, possibly because the added heat sink of the ice slurry was not sufficient to counteract the heat accumulation of the exercise in the hot environment. Therefore, the participants maintained the same sweat rate while taking advantage of the ice slurry heat sink in 
an attempt to stay closer to homeostasis. Evaporative cooling plus ice slurry in the FS trial was able to attenuate the rise in core temperature and heart rate after 3 hours of exercise.

Previous studies have found that humans can withstand and even thrive when about $2 \%$ body mass loss is incurred during work/exercise in hot environments. However, most of these studies only describe the outcomes of individuals exercising and consuming fluid ad libitum and do not show comparisons with the same individuals consuming fluid at a rate to maintain euhydration. ${ }^{26-28}$ In the studies that make direct comparisons, hypohydration of 2 to $3 \%$ of body mass can increase rectal temperature 0.2 to $0.6^{\circ} \mathrm{C}$ and increase heart rate 5 to 9 beats $\cdot \mathrm{min}^{-1}$ without affecting selfselected performance. ${ }^{3-6,29-33}$ Our data indicate no differences in heart rate or rectal temperature when individuals experienced approximately $2 \%$ body water loss while consuming ice slurry compared with maintaining near euhydration when consuming ambient temperature water. The heat sink provided by the ice slurry of the HS trial, when added to the high sweat rate seen in FS, HS, and W, may have been enough to eliminate the small increase in rectal temperature and heart rate associated with approximately $2 \%$ body water loss shown in previous studies.

Plasma electrolyte concentrations are important for proper performance and safety while exercising in hot conditions. Large increases in plasma electrolyte concentration due to underdrinking and large decreases due to overdrinking should be avoided. Despite changes in concentration from pre- to post-trial, all measured electrolytes (ie, sodium, chloride, and potassium) remained within the normal expected physiological range.

\section{LIMITATIONS AND CONSIDERATIONS}

Consuming half the recommended volume is not necessarily the optimal fluid volume when consuming ice slurry. Additionally, consuming very cold fluid without ice may not provide the same thermoregulatory response as ice slurry. Future studies should investigate the balance of trading fluid temperature for volume on thermoregulation and performance. More cardiovascular measures, such as stroke volume and skin blood flow would have provided additional insight into the mechanisms underlying the results of the present study. Although the present study was sufficiently powered to investigate the primary outcomes of thermoregulation and hydration status, future studies could include larger sample sizes to elucidate the underlying mechanisms, such as a decreased sweat rate or plasma volume change with slurry ingestion.

\section{Conclusions}

This study suggests that consuming the recommended volume of fluid delivered as ice slurry provided the best protection against hyperthermia during this study. However, this study also suggests that consuming half the volume of ice slurry results in a thermoregulatory condition similar to consuming the recommended volume of ambient temperature fluid. Therefore, individuals working in hot environments should be mindful of both the volume and temperature of the fluid they consume. Further research should be done to determine impact that exchanging fluid temperature for fluid volume has on exercise performance.

Author Contributions: Study Concept and design (WH, JC, BR), obtaining funding (BR, WH, JC), acquisition of data (WH, JC, KC, $\mathrm{BR}$ ), analysis of the data: (WH, KC), drafting of the manuscript: (WH, $\mathrm{KC}$ ), critical revision of the manuscript: (JC, BR), approval of final manuscript (BR).

Financial/Material Support: We would like to thank the United States Air Force for research funding to complete this project: grant number FA8650-15-2-6602.

Disclosures: The views expressed in this article are those of the authors and do not necessarily reflect the official policy or position of the Air Force, the Department of Defense, or the US Government.

\section{References}

1. Ruby B, Cuddy J, Hailes W, et al. Extreme endurance and the metabolic range of sustained activity is uniquely available for every human not just the elite few. Comp Exerc Physiol. 2015;11:1-17.

2. McLellan T. Maintaining hydration: issues, guidelines, and delivery. Technical evaluation report RTO-MP-HFM-086. Proceedings of the RTO Human Factors and Medicine Panel Specalists' Meeting. Dec 10-11, 2003 Boston, MA: Neuilly-Sur-Seine Cedex, France; NATO Science and Technology Organization; 2004. T-3.

3. Sawka MN, Toner MM, Francesconi RP, Pandolf KB. Hypohydration and exercise: effects of heat acclimation, gender, and environment. J Appl Physiol Respir Environ Exerc Physiol. 1983;55:1147-1153.

4. Sawka MN, Young AJ, Francesconi R, Muza S, Pandolf KB. Thermoregulatory and blood responses during exercise at graded hypohydration levels. J Appl Physiol. 1985; 59:1394-1401.

5. Ekblom B, Greenleaf CJ, Greenleaf JE, Hermansen L. Temperature regulation during exercise dehydration in man. Acta Physiol Scand. 1970;79:475-483.

6. Montain SJ, Coyle EF. Influence of graded dehydration on hyperthermia and cardiovascular drift during exercise. J Appl Physiol. 1992;73:1340-1350.

7. Montain SJ, Latzka WA, Sawka MN. Fluid replacement recommendations for training in hot weather. Mil Med. 1999; 164:502.

8. Sawka MN, Burke LM, Eichner ER, Maughan RJ, Montain SJ, Stachenfeld NS. American College of Sports 
Medicine position stand. Exercise and fluid replacement. Med Sci Sports Exerc. 2007;39:377-390.

9. Lee JK, Shirreffs SM. The influence of drink temperature on thermoregulatory responses during prolonged exercise in a moderate environment. J Sports Sci. 2007;25:975-985.

10. Lee J, Shirreffs SM, Maughan RJ. Cold drink ingestion improves exercise endurance capacity in the heat. Med Sci Sports Exerc. 2008;40:1637-1644.

11. Wimer GS, Lamb DR, Sherman WM, Swanson SC. Temperature of ingested water and thermoregulation during moderateintensity exercise. Can J Appl Physiol. 1997;22:479-493.

12. Stanley J, Leveritt M, Peake JM. Thermoregulatory responses to ice-slush beverage ingestion and exercise in the heat. Eur J Appl Physiol. 2010;110:1163-1173.

13. Burdon C, O'Connor H, Gifford J, Shirreffs S, Chapman P, Johnson N. Effect of drink temperature on core temperature and endurance cycling performance in warm, humid conditions. J Sports Sci. 2010;28:1147-1156.

14. Siegel R, Mate J, Brearley MB, Watson G, Nosaka K, Laursen PB. Ice slurry ingestion increases core temperature capacity and running time in the heat. Med Sci Sports Exerc. 2010;42:717-725.

15. Mündel T, King J, Collacott E, Jones DA. Drink temperature influences fluid intake and endurance capacity in men during exercise in a hot, dry environment. Exp Physiol. 2006;91:925-933.

16. Bain A, Lesperance N, Jay O. Body heat storage during physical activity is lower with hot fluid ingestion under conditions that permit full evaporation. Acta Physiol (Oxf). 2012;206:98-108.

17. Burdon CA, Hoon MW, Johnson NA, Chapman PG, O'Connor HT. The effect of ice slushy ingestion and mouthwash on thermoregulation and endurance performance in the heat. Int J Sport Nutr Exerc Metab. 2013;23:458-469.

18. Lee JK, Maughan RJ, Shirreffs SM. The influence of serial feeding of drinks at different temperatures on thermoregulatory responses during cycling. J Sports Sci. 2008;26: 583-590.

19. US Air Force. Thermal Injury. Washington, DC: Department of the Air Force; 200248-151.

20. Siri WE. Body composition from fluid spaces and density: analysis of methods. In: Brozek J, Henschel A, eds. Techniques for Measuring Body Composition. National Academy of Sciences, National Research Council: Washington, DC; 223-244.

21. Bruce RA, Kusumi F, Hosmer D. Maximal oxygen intake and nomographic assessment of functional aerobic impairment in cardiovascular disease. Am Heart J. 1973;85:546-562.

22. Moran DS, Shitzer A, Pandolf KB. A physiological strain index to evaluate heat stress. Am J Physiol. 1998;275: R129-R134.

23. Mitchell JW, Nadel ER, Stolwijk J. Respiratory weight losses during exercise. J Appl Physiol. 1972;32:474-476.

24. ACSM's Metabolic Calculations Handbook. In: Glass S, Dwyer GB, eds Baltimore, MD: Lippincott Williams \& Wilkins; 2007:25-74.

25. Fox EL, Bowers RW, Foss ML, Fox EL. The Physiological Basis for Exercise and Sport. Madison, WI: Brown \& Benchmark Publishers; 1993.

26. Nolte H, Noakes TD, Van Vuuren B. Ad libitum fluid replacement in military personnel during a 4-h route march. Med Sci Sports Exerc. 2010;42:1675-1680.

27. Nolte HW, Noakes TD, van Vuuren B. Protection of total body water content and absence of hyperthermia despite $2 \%$ body mass loss ('voluntary dehydration') in soldiers drinking ad libitum during prolonged exercise in cool environmental conditions. Br J Sports Med. 2011;45: 1106-1112.

28. Lee JK, Nio AQ, Lim CL, Teo EY, Byrne C. Thermoregulation, pacing and fluid balance during mass participation distance running in a warm and humid environment. Eur J Appl Physiol. 2010;109:887-898.

29. Dion T, Savoie FA, Asselin A, Gariepy C, Goulet ED. Half-marathon running performance is not improved by a rate of fluid intake above that dictated by thirst sensation in trained distance runners. Eur J Appl Physiol. 2013;113: 3011-3020.

30. Dugas J, Oosthuizen U, Tucker R, Noakes T. Rates of fluid ingestion alter pacing but not thermoregulatory responses during prolonged exercise in hot and humid conditions with appropriate convective cooling. Eur J Appl Physiol. 2009;105:69-80.

31. Gigou P-Y, Dion T, Asselin A, Berrigan F, Goulet ED. Preexercise hyperhydration-induced bodyweight gain does not alter prolonged treadmill running time-trial performance in warm ambient conditions. Nutrients. 2012;4:949-966.

32. Robinson TA, Hawley JA, Palmer GS, et al. Water ingestion does not improve 1 -h cycling performance in moderate ambient temperatures. Eur J Appl Physiol Occup Physiol. 1995;71:153-160.

33. Merry T, Ainslie P, Cotter J. Effects of aerobic fitness on hypohydration-induced physiological strain and exercise impairment. Acta Physiol (Oxf). 2010;198:179-190. 